\title{
SOBRE OS PRESSUPOSTOS ONTOLÓGICOS DA LIBERDADE*
}

Resumo: $O$ objetivo principal do presente artigo consiste na explicitação da constituição ontológica do sujeito ao qual são atribuídas ações livres. Será mostrado em que medida a afirmação de que um sujeito age livremente pressupõe, por um lado, a diferenciação, no interior do sujeito, entre esferas volitivas de natureza diversa, e, por outro, a afirmação de que este não é idêntico ao conjunto de suas volições, consistindo, em ultima instância, em um puro poder formal de criação e adoção de "imagens de si". palavras-chave: Liberdade, Metafísica, Ontologia.

Abstract: My main concern in this paper is to explicit the ontological constitution of the agent to whom free actions are assigned. I will show how the assertion that a certain agent acts freely pressuposes, on one hand, that there are two different kinds of volitions, and, on the other hand, that this agent cannot be identical to the whole set of his volitions. He is, lastly, a pure formal power of invention and adoption of "images of the self". Key words: Freedom, Metaphysics, Ontology

"Devo minha introdução à problemática tratada neste artigo ao professor Lorenz Puntel da Universidade de Munique. Graças a uma bolsa de pesquisa a mim concedida pelo DAAD e pela CAPES, tive a feliz oportunidade de assistir no semestre de inverno 1999-2000 na Universidade de Munique a um excelente curso do professor Puntel sobre o problema filosófico da liberdade. O curso e nossas discussões privadas acerca do tema encorajaram-me a escrever este texto. Agradeço ao DAAD e à CAPES pelo apoio recebido e ao professor Puntel por sua generosidade intelectual e humana. 

certos sujeitos agem livremente. Tentarei, dessa maneira, mostrar que condições ontológicas devem ser necessariamente satisfeitas para que se possa atribuir, de forma coerente, liberdade a determinados sujeitos. Trata-se, então, neste texto, antes de uma determinação da estrutura ontológica de um mundo no qual seres livres existam do que propriamente de uma demonstração de que certos entes - os seres humanos, por exemplo - são seres livres. Em outros termos, o que pretendo efetivamente é desvelar alguns dos postulados ontológicos que temos de aceitar quando consideramos que somos livres, e não provar que somos livres. A tarefa à qual me dedico neste artigo é prévia, portanto, à formulação de uma resposta à questão de se somos ou não livres, limitando-se essa tarefa à explicitação, por assim dizer, do ônus ontológico da liberdade. Se devemos ou não arcar com esse ônus é algo cuja resposta escapa às dimensões deste artigo.

Na primeira seção mostro que uma ação somente pode ser caracterizada como livre quando (1) a causa da ação do sujeito é imanente ao sujeito da ação e (2) quando se considera que o sujeito da ação pode controlar seus estados internos que causam suas ações. Na segunda seção explicito a ontologia do sujeito pressuposta pela atribuição a este dessa possibilidade de controle sobre o poder causal das próprias volições, tornando claro que tal atribuição implica em uma distinção, no interior do sujeito, entre dois tipos diversos de volições, sendo a identidade do sujeito determinada unicamente pelas volições de um determinado tipo. Na terceira seção mostro que é inevitável uma radicalização dos resultados obtidos na seção precedente e que nos leva a diferenciar o sujeito do conjunto de todas suas volições. O sujeito livre deve ser compreendido, assim, como consistindo simplesmente em um puro e formal poder de auto-posição.

Uma ação é livre unicamente na medida em que ela é livremente realizada. Isto é, a caracterização de uma ação como sendo livre expressa uma declaração acerca de seu modo de efetuação. Isso significa que o recurso aos predicados descritivos utilizados para individuarmos as diversas ações e diferenciá-las umas das outras é insuficiente como base para o julgamento acerca do caráter livre ou não-livre das ações, pois nada parece impedir que uma "mesma" ação seja realizada ora de 
forma livre e ora de forma não-livre'. Mais grave ainda: é possivel que, em um determinado instante $t_{l}$, interpretemos uma certa ação $a$ realizada por um sujeito $s$ como livre, sendo levados, em um momento

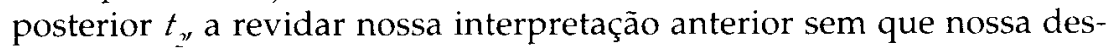
crição da ação ela mesma tenha de ser corrigida. Digamos, por exemplo, que esse sujeito $s$ tenha roubado um objeto qualquer. $S$ terá agido livremente, e será por nós moral e judicialmente responsabilizado pelo seu ato, caso consideremos que ele, quando de sua ação, tinha "à sua disposição" um repertório de ações possíveis, tendo optado por uma delas independentemente do exercício sobre ele de forças coercitivas a ele externas. $S$ terá agido livremente, em outras palavras, (1) se sua ação puder ser caracterizada como expressão de sua própria vontade e (2) se tiver sido produto de uma sua escolha.

Que ambas as condições devem ser satisfeitas para que a ação seja dita livre fica claro se levarmos em conta que tanto em caso de hipnose a vontade de roubar é imposta ao sujeito $s$ pelo hipnotizador - como no caso da cleptomania - o compulsivo não escolhe em sentido forte seu modo de ação - o referido sujeito $s$ não é pensado como tendo agido livremente. O que esses dois exemplos de ação não-livre parecem indicar é que um sujeito é dito livre ao agir quando a causa de sua ação for um estado intensional interno ao próprio sujeito agente ${ }^{2}$ e a consumação ou não da ação correspondente a esse estado intensional encontrar-se sob o controle desse mesmo sujeito. Para tornar mais claras essas duas condições, explorarei com um pouco mais devagar os exemplos introduzidos.

O sujeito que, durante um transe hipnótico, realiza a ação de roubar não é considerado responsável pelo seu ato, uma vez que não foi sua própria vontade o móvel da ação, mas sim a vontade do hipnotizador. Sua ação não é, portanto, livre pelo fato da causa dela localizar-se não no sujeito mesmo, mas em uma instância a ele exterior. Ações são livres, assim, unicamente na medida em que a vontade que as causa encontrase no próprio sujeito que as realiza. Quando afirmamos que uma determinada ação é livre estamos, então, afirmando algo acerca de sua causa produtora, nomeadamente, que ela se encontra no interior do sujeito agente. A idéia fundamental sobre a qual se apóia, dessa maneira, nossa intuição cotidiana de que sujeitos hipnotizados não são livres - e que, portanto, são inimputáveis relativamente aos atos praticados sob hipnose - é a de que só há liberdade quando estados internos do

\footnotetext{
1 Uma vez que ações são eventos de natureza espácio-temporal é claro que, em um sentido estrito, a mesma ação não pode ser realizada duas vezes. Refiro-me aqui, mais apropriadamente, a uma identidade entre types e não entre tokens. 2 Dito de outro modo: quando vigora uma relação de causalidade imanente entre a ação do sujeito e o sujeito da ação.
} 
sujeito -- volições - são causalmente responsáveis pelas ações por esse praticadas. A atribuição de liberdade a uma ação praticada por um certo sujeito identifica-se, ao menos parcialmente, à atribuição de responsabilidade causal aos estados volitivos desse sujeito relativamente a essa ação. Se, por oposição à nossa visão do hipnotizado, consideramonos livres é porque tomamos por certo que nossas ações têm por causa nossas volições, isto é, que, nos limites de nosso poder de determinação da realidade, fazemos o que queremos, e não o que outros possam por ventura querer.

Entretanto, a idéia de que o sujeito somente é livre ao agir quando a causa da ação lhe é imanente não parece capturar todos os elementos conceituais presentes em nossa concepção cotidiana de liberdade, como bem o pode ilustrar o caso do cleptomaníaco. Alguém que rouba compulsivamente é alguém que age a partir de volições a ele internas, sem que se possa responsabilizar nenhum terceiro pelas açōes praticadas pelo primeiro. Mesmo assim, seria extremamente problemático tratar da mesma forma os furtos realizados por um cleptomaníaco e os cometidos por um ladrão comum. Ambos agem a partir de desejos internos, mas enquanto atribuímos ao ladrão comum a possibilidade de escolher dentre seus desejos qual deles adquirirá o poder causal de produção da ação a ser realizada, o cleptomaníaco é visto, ao contrário, como alguém que não possui controle sobre o próprio comportamento, como alguém que não dispõe, em última instância, da capacidade de determinação do próprio modo de ação. Apesar do desejo de roubar ser um desejo do próprio cleptomaníaco, considera-se que esse desejo impõe-se a ele de uma forma tão irresistível, que a ele não resta nenhuma escolha além da execução dos roubos para os quais ele é internamente necessitado. O que caracteriza a cleptomania não é, então, propriamente o desejo constante de roubar, mas sim a incapacidade de resistir a esse desejo quando ele se apresenta. $O$ desejo de roubar adquire, assim, o poder causal de produção do comportamento independentemente de todas as deliberações que o sujeito possa realizar tendo em vista seus modos futuros de ação. É exatamente a atribuição ao cleptomaníaco dessa incapacidade de controle do próprio comportamento que justifica o fato de suas ações serem vistas como patológicas e não propriamente como criminosas. É por isso que ele é visto como alguém que necessita de acompanhamento psicológico e não de execração moral ou de punição judicial.

O que se encontra por trás dessa diferença de postura diante de ações semelhantes consiste na idéia de que há um déficit de liberdade por parte do agente quando alguns dos desejos nele presentes causam uma determinada ação sem que o próprio agente tenha o poder de impedir que isso ocorra. Isso indica que nossa concepção cotidiana de liberdade - a qual possibilita que a expressão "comportamento compulsivo faça 
algum sentido - envolve não só a autonomia do agente face a coerções externas, mas também uma certa autonomia deste face a seus próprios desejos. O sujeito somente age livremente quando sua ação reflete uma escolha por ele realizada dentre alternativas concorrentes que a ele se apresentam. Quando o sujeito é considerado impotente para impedir que um certo seu desejo produza uma determinada ação, essa ação é vista como não-livre, e o sujeito não é tido por moralmente responsável por ela em função do fato de não possuir controle efetivo sobre sua realização?

O que o caso do cleptomaníaco parece nos ensinar acerca do modo como concebemos a liberdade é que essa implica que da subsistência nos agentes de determinados desejos não se segue imediatamente a realização das ações adequadas à sua satisfação, tendo de haver, ao contrário, para que possamos considerar que o sujeito em questão age livremente, uma instância de deliberação e de controle que seja interna a este.

Creio que essa idéia de controle envolve, por um lado, a distinção entre dois tipos diversos de desejos no interior do sujeito e, por outro, a distinção entre o sujeito livre e a "imagem de si" $^{\prime \prime}$ por ele formada. Tratarei da primeira distinção na próxima seção e da segunda na seção subseqüente.

O que há, como vimos, de característico no caso do cleptomaníaco é sua incapacidade de impedir que um certo desejo seu seja o fator determinador de sua ação. Independentemente do modo que ele queira se comportar, será o desejo de roubar que se imporá aos outros desejos e que fará com que ele roube. O cleptomaníaco não é livre exatamente porque seu desejo de que o desejo de roubar não produza a ação de roubar não consegue evitar que esse desejo desencadeie a ação do roubo. O controle que falta ao cleptomaníaco consiste precisamente na capacidade de tornar eficaz desejos que têm por objeto outros desejos. Nesse sentido, livre será aquele cujos desejos desencadeadores do próprio comportamento sejam, por sua vez, desejados pelo sujeito como

"Em seu texto "Aiternate Possibilities and Moral Responsibility", HaRRY FrankfurT defende a idéia de que pode haver responsabilidade moral mesmo não havendo uma alternativa real para o sujeito agente. A concepção de Frankfurt pareceme equivocada, mas não argumentarei contra ela no presente texto.

"No que se segue utilizarei as expressões "imagem de si", "imagem de pessoa", "projeto de si" e "projeto de pessoa" em um sentido intercambiável. 
portadores dessa eficácia causal. Isto é, tem-se controle do próprio comportamento quando são eficazes os desejos de que as próprias ações sejam deflagradas por certos desejos determinados.

A idéia de controle, introduzida para dar conta do déficit de liberdade atribuído ao comportamento compulsivo, implica, assim, a elaboração de uma distinção entre, por um lado, desejos que de alguma maneira têm outros desejos por objeto e, por outro lado, desejos que servem de objeto para os primeiros. Lançando mão aqui da terminologia introduzida por Harry Frankfurt ${ }^{5}$, eu gostaria de chamar de "desejos de primeira ordem" aos desejos de se fazer isso ou aquilo (ou de se ter isso ou aquilo), reservando a expressão "desejos de segunda ordem" para os desejos de que certos desejos de se fazer isso ou aquilo sejam - ou não sejam, pouco importa - causalmente eficazes relativamente à produção do próprio comportamento ${ }^{\phi}$. Quando se tem um determinado desejo de segunda, ordem não se deseja, então, diretamente fazer isso ou aquilo, mas sim deseja-se que um certo desejo de primeira ordem determine a própria ação.

Que desejos de primeira e de segunda ordem não possuem o mesmo conteúdo - e que não podem, portanto, ser idênticos uns aos outros - fica claro se pensarmos, por exemplo, na diferença entre desejar trabalhar e desejar que se deseje trabalhar. No primeiro caso, deseja-se uma atividade, enquanto no segundo deseja-se ter o desejo de realizar tal atividade. O segundo desejo tem por objeto, dessa maneira, não a atividade propriamente dita, mas sim uma circunstância na qual o desejo por essa atividade seja tão forte a ponto de determinar a própria ação.

Poder-se-ia argumentar contra a distinção entre esses dois tipos de desejo lançando-se mão da idéia de que as condições de satisfação de um desejo é que possibilitam a determinação do conteúdo intensional desse desejo. Isto é, a determinação daquilo que é desejado dar-se-ia, segundo essa concepção, através da fixação do que deve ocorrer no mundo para que esse desejo seja satisfeito. Sendo assim, o objeto do desejo coincidiria com o estado de coisas que deve ocorrer no mundo para que esse desejo encontre sua satisfação.

\footnotetext{
${ }^{5}$ Em seu texto Freedom of the Will and the Concept of a Person, Journal of Philosophy vol. LXVIII 1971): 5-20. Citarei, contudo, nas notas subseqüentes seguindo o texto impresso em G. Watson (ed.), Free Will, Oxford: Oxford University Press, 1982, 81-95.

"Nos termos de Frankfurt: "Someone has a first-order desire when he wants to do or not to do such-and-such, and he has a second-order desire when he wants to have or not to have a certain desire of the first order", in H. FrANKFurT, op. cit., 83 .
} 
Se aplicarmos essa concepção semântica ao exemplo da distinção entre desejos acima apresentado, veremos que os conteúdos do desejo de primeira e do de segunda ordem parecem colapsar em um único conteúdo, pois ambos os desejos são satisfeitos quando o sujeito realiza a atividade de trabalhar. Ora, se os dois desejos possuem a mesma condição de satisfação, então eles possuem o mesmo conteúdo e não podem, portanto, serem distinguidos um do outro. $O$ mesmo ocorreria em todos os casos em que se tentasse introduzir uma distinção entre o desejo por $x$, por um lado, e o desejo de desejar $x$, por outro.

Esse contra-argumento pode ser refutado de duas formas distintas: pode-se ou rejeitar a teoria semântica que lhe serve de base ou negar que se tenha determinado com a precisão devida a condição de satisfação do desejo de segunda ordem. Uma vez que concordo com a teoria semântica apresentada - não podendo, contudo, por razões de economia, expor aqui as razões que me levam a aderir a ela -, resta-me considerar a segunda hipótese. E realmente parece-me falso dizer que, mantendo a referência ao exemplo introduzido mais acima, a atividade de trabalhar seja a condição de satisfação tanto do desejo de trabalhar quanto do desejo de que se deseje trabalhar, pois, caso o exercício dessa atividade tenha uma causa outra que o efetivo desejo do sujeito $^{7}$, não se pode considerar que ele satisfaça o desejo de que se deseje trabalhar. Isto é, trabalhar satisfaz o desejo de trabalhar, mas o desejo de que se deseje trabalhar somente é satisfeito quando o exercício dessa atividade é realmente desencadeado pelo desejo de trabalhar, e não por uma outra causa qualquer. Dessa maneira, não é o mero exercício da atividade de trabalhar que satisfaz a esse desejo de segunda ordem, mas sim a ocorrência no sujeito do desejo de trabalhar associada à determinação do comportamento do sujeito por parte desse desejo de primeira ordem. Sendo distintas as condições de satisfação desses desejos, não há por que considerar que eles possuam o mesmo conteúdo intensional. O desejo por $x$ é satisfeito por $x$, enquanto o desejo de que se deseje $x$ é satisfeito, ao contrário, por $x$-sendo-causado-pelo-desejo-por-x.

Desejos de segunda ordem tratam, por assim dizer, por conseguinte, e aqui avanço uma conclusão não retirada explicitamente por Frankfurt - não propriamente de estados de coisas no mundo, mas sim do sujeito mesmo desses desejos. Isto é, quando se tem um desejo de segunda ordem, o que se deseja não é propriamente que o mundo se apresente dessa ou daquela forma, mas sim deseja-se ser desse ou 7 Podemos pensar nesse contexto, por exemplo, em casos nos quais o sujeito
acabe trabalhando não por desejo próprio, mas sim por medo de sançóes sociais. 
daquele modo. O que um desejo de segunda ordem expressa é, portanto, uma certa representação do sujeito acerca do modo de ser que esse sujeito julga que deveria ser seu próprio. O foco de um desejo de segunda ordem é uma certa "imagem de si" do sujeito desse desejo, a qual ele deseja ver em si mesmo realizada, e não uma imagem do mundo ${ }^{\varnothing}$.

Ao desenvolver, então, desejos de segunda ordem, o sujeito coloca-se, ao mesmo tempo, nas posições de juiz e de modelador do próprio comportamento. Quer dizer, os desejos de segunda ordem devem servir como critério para a escolha dos desejos de primeira ordem a serem comportamentalmente implementados pelo sujeito. É o conjunto desses desejos de segunda ordem que constitui a imagem formada pelo sujeito acerca da pessoa que ele acha que deve ser. Essa imagem é que fornece as diretrizes a partir das quais o sujeito pauta suas escolhas.

O que caracteriza o agente livre é exatamente essa possibilidade de determinar sua própria ação a partir da imagem ideal que ele forma de si. Nesse sentido, não é livre nem o sujeito que simplesmente satisfaz seus desejos de primeira ordem sem deliberar se a realização dessa ação corresponde à imagem do tipo de pessoa que ele acha que deve ser, nem o sujeito cujos desejos de segunda ordem são ineficazes relativamente à determinação do grau de eficácia causal dos desejos de primeira ordem. A diferença entre os dois reside no fato de que o segundo se sente como não-livre, enquanto o primeiro encontra-se aquém desse dilema. Animais e crianças pequenas exemplificam o primeiro tipo, pessoas com comportamento compulsivo o segundo.

Para que possamos, de maneira coerente, caracterizar o comportamento compulsivo como sendo não-livre, apesar do fato de suas causas serem internas ao sujeito, temos, então, de introduzir uma distinção, no interior dos sujeitos agentes, entre duas esferas volitivas de naturezas diversas, e considerar que a identidade do sujeito (isto é, quem ele crê efetivamente ser) é determinada pelos seus desejos de segunda ordem 4 .

\footnotetext{
"É precisamente por essa referència à auto-imagem do sujeito que eu creio que os desejos de segunda ordem não devem ser compreendidos simplesmente como desejos mediatos, por oposição aos desejos de primeira ordem, que seriam imediatos. A oposição mediato-imediato - apesar de poder ser vista como sendo, em última instância, correta - nâo nos ajuda a avançar na compreensão das relações subsistentes entre o conceito de auto-controle e o de liberdade. A insistência em compreender essa oposição unicamente nesse sentido é, creio, empobrecedora da discussão.

${ }^{9}$ Watson compreende essa distinção como sendo entre uma esfera volitiva e uma valorativa, sendo o segundo o determinador da identidade do agente (ver: $G$ Watson, Free agency, in IDFm, (ed.), Free will, Oxford: Oxford University Press, $1982,106)$.
} 
Somente dessa maneira podemos tornar compreensível a idéia de que, por exemplo, o desejo do cleptomaníaco de roubar seja considerado como algo que se impõe a ele independentemente da sua própria vontade, padecendo este, portanto, relativamente a esse comportamento, de um certo déficit de liberdade em função da ausência do auto-controle.

O que fica pressuposto nessa descrição é que quem o cleptomaníaco é - isto é, a pessoa que ele é - não é determinado propriamente pelo desejo de roubar, mas sim pelo desejo - causalmente ineficaz - de que o desejo de roubar não desencadeie a ação de roubar. $\mathrm{O}$ cleptomaníaco identifica-se, portanto, não com seus desejos dirigidos ao mundo (desejos de primeira ordem), mas sim com os desejos que têm por objeto uma imagem de como os seres humanos devem ser e comportar-se (desejos de segunda ordem) ${ }^{10}$. Por isso as ações desencadeadas diretamente pelos seus desejos de primeira ordem lhe são estranhas e exteriores. Em um certo sentido, ele não as sente como ações por ele realizadas, pois elas não se conformam ao modelo de "eu" que ele desejaria impor a si mesmo e que ele vê como sendo seu "eu próprio". O seu déficit de liberdade consiste precisamente nessa impossibilidade de auto-determinação - auto-controle - e é por esse motivo que ele não se sente livre nem é visto como sendo livre.

É também o reconhecimento dessa ausência de auto-controle que faz com que não haja reprovação moral ou punição judicial pelos atos praticados por comportamento comprovadamente compulsivo. Isso indica que o real objeto de nossas puniçōes ou reprovaçôes reside não na ação ela mesma, mas sim diz respeito ao comportamento unicamente na medida em que se reconhece nele a encarnação de uma imagem formada pelo sujeito acerca do tipo de pessoa que ele quer ser. Quanto mais clara for essa correlação entre ação e imagem ${ }^{11}$, maior será a indignação provocada por um ato criminoso. Daí serem as emoções fatores atenuantes e o "sangue-frio" um fator agravante em qualquer julgamento moral ou judicial de ações. Daí as reaçōes negativas provocadas por aquele que não se arrepende de suas ações judicial ou moralmente condenadas. O objeto da indignição parece ser, neste caso, não propriamente as ações realizadas, uma vez que o distanciamento em relação a elas e o arrependimento de tê-las cometido fariam com que

\footnotetext{
11" Não se trata aqui, contudo, apenas de um caso de auto-interpretação. Todas essas considerações valem mutatis mutandi para a perspectiva daqueles que caracterizam alguém como sendo cleptomaníaco.

"Isto é, quanto mais evidente for que a ação realizada corresponde à imagem de si formulada pelo agente, reconhecendo-se este, portanto, plenamente nessa ação.
} 
o agente fosse julgado de modo mais benevolente, mas sim a perseverante adoção de um certo "modelo de pessoa".

A partir do que foi dito nas seçoes precedentes, poderíamos, aparentemente, caracterizar o sujeito livre como sendo aquele que (1) formula uma "imagem de $\mathrm{si}^{\prime \prime}$ - um "projeto de $\mathrm{si}^{\text {" - }}$ - e que (2), tomando essa imagem como modelo, controla os próprios desejos de primeira ordem, de modo a tornar causalmente produtores do próprio comportamento apenas aqueles desejos que forem adequados a essa imagem. As ações de um sujeito livre podem ser vistas, assim, como expressão da implementação de um "projeto de si" por parte desse sujeito. O grau de liberdade dessas ações será diretamente proporcional à capacidade de auto-controle - ou auto-determinação - que o sujeito possuir. Isto é, será mais livre o sujeito que tiver mais êxito nesse processo de fixação, tendo como base a imagem adotada, de seus desejos de primeira ordem que possuirão eficácia causal relativamente ao próprio comportamento. A liberdade consistiria, assim, em última instância, na capacidade do sujeito de implementar em si mesmo o "projeto de pessoa" escolhido por ele mesmo. As ações não-livres seriam, portanto, aquelas nas quais o sujeito, por ausência de auto-controle - caso do cleptomaníaco - ou de vontade própria - caso do hipnotizado --, agisse em contradição com seu próprio projeto.

Se as ações são tidas por não-livres quando entram em contradição com o "projeto de pessoa" adotado pelo agente, então poderíamos dizer que o sujeito age livremente quando ele consegue adequar os meios dos quais ele dispõe - seu repertório de ações - aos fins que ele busca a realização em si de seu "eu ideal". A caracterização de uma ação como livre expressaria, desse modo, simplesmente a avaliação de que (1) a ação corresponde ao "projeto de pessoa" concebido pelo sujeito agente e (2) que essa correspondência não é casual nem produzida por algum fator externo ao sujeito, devendo-se, ao contrário, unicamente a um esforço pessoal deste. A ação livre é, dessa maneira, racional - no sentido restrito de uma racionalidade instrumental -- porque a própria caracterização de liberdade quando aplicada às ações envolve a idéia de adequação entre fins e meios.

Entretanto, essa concepção de liberdade assim formulada ainda é parcial e insuficiente - embora seja, do meu ponto de vista, correta -, pois ela diz respeito apenas às relações subsistentes entre o sujeito e suas ações, sendo a liberdade, a partir dela, algo presente unicamente quando ao agir o sujeito determina seu próprio comportamento, tendo em 
vista sua esfera valorativa, isto é, seus desejos de segunda ordem. Ser livre consistiria em conseguir agir de acordo com a imagem do tipo de pessoa que se quer ser.

Ao compreendermos a liberdade nesses termos, não podemos, contudo, obviamente, dar conta da própria escolha que o sujeito faz do "projeto de $\mathrm{si}^{\prime \prime}$ por ele adotado. Isto é, essa concepção de liberdade não contempla a escolha realizada pelo sujeito da imagem que ele toma como sendo aquela de seu "eu ideal". Caso essa imagem seja impingida ao agente em questão por algum sujeito ou força exteriores a ele, torna-se absurda a atribuição de liberdade àquele que realiza suas ações a partir dela. A idéia de liberdade parece exigir, portanto, que essa própria "imagem de pessoa" seja assumida livremente pelo sujeito que a toma como paradigma. Isto é, o sujeito livre deve não apenas controlar e determinar seu próprio comportamento a partir de um modelo, mas sim fixar também de modo autônomo esse modelo mesmo.

Enquanto a realização livre das ações é guiada pela idéia de implementação comportamental da "imagem de pessoa" aceita pelo agente, a escolha dessa imagem mesma não pode ser realizada sobre a base de considerações de qualquer outra natureza, pois não há nenhum parâmetro de julgamento mais amplo e fundamental que essa imagem. É ela que congrega o conjunto de valores fundamentais a partir dos quais o sujeito realiza suas opções. É ela que, em última instância, fornece as razões últimas que justificam a escolha de um certo modo de agir em detrimento de outros possíveis. A escolha de uma certa "imagem de pessoa" não pode, então, ser justificada através do recurso a uma determinada opção mais fundamental ainda, de tal maneira que essa escolha pudesse ser vista como uma mera implementação de um projeto prévio a ela. Isso significa que a caracterização do sujeito como livre parece exigir que se pressuponha um "descolamento" entre o sujeito e sua esfera valorativa última, sendo este livre unicamente na medida em que se encontra em seu poder assumir, independentemente de qualquer fator a ele externo, uma "imagem de si".

Uma vez que é precisamente essa "imagem de si" que constitui, como dissemos mais acima, a identidade substantiva do sujeito, esse "si" mais fundamental que realiza a opção livre por uma certa "imagem de si" somente pode possuir uma identidade meramente formal. Isto é, a afirmação de que um certo sujeito é livre implica a afirmação de que esse sujeito, em última instância, caracteriza-se por ser simplesmente um poder de auto-posição ${ }^{12}$, quer dizer, um poder de constituição da

\footnotetext{
${ }^{12}$ Essa afirmação é inpirada pelas consideracões de Thomas Reid acerca da liberdade humana como fundada no que ele chama de "active power". Ver: Thomas Reid, Essay on the Active Powers of the Human Mind, Cambridge: MIT Press, 1969.
} 
"imagem de si" a ser por ele próprio adotada. Não há identidade, portanto, entre o sujeito e a "imagem de si" que ele adota.

A atribuição da liberdade a um sujeito implica, assim, a afirmação de que nem a esfera volitiva nem a esfera valorativa dele são a ele idênticos. O sujeito livre deve ser entendido, então, não como uma substância dotada de uma identidade fixada a partir de um conjunto específico de características, mas sim como um puro poder formal de criação e adoção de "imagens de si".

Endereço do Autor:

Rua Teixeira de Freitas, 140/301

30350-180 Belo Horizonte - MG

e-mail: edgar@fafich.ufmg.br 